\title{
An investigation of long-distance dispersal based on species native to both Tasmania and New Zealand
}

\author{
Gregory J. Jordan
}

School of Plant Science, University of Tasmania, GPO Box 252-55, Hobart, Tas. 7001, Australia.

E-mail: greg.jordan@utas.edu.au

Abstract. Some 200 species of plants are currently recognised as being native to both Tasmania and New Zealand. It is argued that dispersal across the 1500-2000 km Tasman Sea has occurred in all of these species. Almost all (187) are herbs, and constitute over $20 \%$ of the herbaceous flora of Tasmania. Common species, non-dioecious species, species with very small seeds, species from aquatic, coastal or wet habitats and possibly species with hooked fruit are all over-represented among the disjunct species of herbs. The incidence of disjunct species also varies significantly among families. In contrast, fleshy-fruited species, or species with plumes or very hairy disseminules are not overrepresented among the herbaceous disjunct species. This data is used to model the probability that a species (past or present) with given traits would show a within-species trans-Tasman disjunction, and it is inferred that this can be used to give a crude approximation of the rates of long-distance dispersal for different types of species. The model can be tested using molecular clock methods, and could be made more robust by incorporating equivalent data from other disjunct regions. 


\section{Introduction}

Cladistic biogeography (e.g. Nelson and Platnick 1981) is a potent approach to reconstructing the geographic history of plants. The most common application of this method reconstructs the geographic history using phylogenies of species endemic to areas separated by dispersal barriers. The working hypothesis (called a vicariant hypothesis) is that branches in the phylogenies correspond to the evolution of these barriers. Thus, the interpretation of area relationships depends on an understanding of what constitutes an effective barrier to dispersal.

Barriers to dispersal can be any intervening regions of unsuitable habitat, but oceans can be major barriers for many land organisms. In fact, there has been long dispute over the significance of trans-oceanic dispersal in plant biogeography. Such events are undoubtedly so rare for most plant groups that experimental data cannot be used to estimate the probability of dispersal. However, even rare successful dispersals can significantly bias the historical interpretation of cladistic biogeographic patterns. This is particularly likely if several taxa follow the same dispersal route (i.e. concerted dispersal). Some biogeographers, such as van Steenis (1979) have argued that dispersal is such a rare event that it can be ignored. In contrast, the nature of floras of islands believed to never have had contact with other landmasses suggests that dispersal across long ocean barriers is significant (Carlquist 1974). Other authors (e.g. Pole 1994; Macphail 1997) have used the fossil record and geological history to argue for dispersal. In opposition to these latter approaches, Nelson and Platnick (1981) argued that dates of the formation of barriers and disjunctions cannot be used to test whether disjunctions are due to vicariance or to dispersal, because dates of geographic events have wide error margins, and that dates from fossils can always be extended backwards by the discovery of older fossils.

The origin of New Zealand's flora has been a particular focus of this vicariancedispersalist debate. New Zealand was part of Gondwana during the Mid Cretaceous but has apparently been separated from other landmasses ever since (Wilford and Brown 1994). Furthermore, the New Zealand flora is rich in endemic species which have relatives in other Gondwanan fragments particularly Australia (van Balgooy 1960, 1971, Allen 1961), and some of these species belong to groups with very long fossil records extending back to the Late Cretaceous or earlier (Mildenhall 1980). Thus, many workers argue that vicariance caused by the break up of Gondwana explains the distribution of 
for many groups, notably Nothofagus (e.g. Linder and Crisp 1995). At the other extreme, Pole (1994) used evidence from geological history, fossils, and the distribution of plants on oceanic islands, to argue that the flora of New Zealand is largely, and perhaps totally, derived from long-distance dispersal.

This work attempts to estimate the probability of dispersal across oceanic barriers for different groups of plants based on ecology and morphology. To do this it considers the species that occur in both Tasmania and New Zealand. It assumes that these disjunctions are the result of long distance dispersal rather than vicariance. This is reasonable since Tasmania and New Zealand are believed to have been geographically disjunct for approximately 80 million years (Wilford and Brown 1994). Thus, vicariant explanations would require that two allopatric populations remained so little changed for 80 million years that they would not be recognised as morphologically distinct species.

Morphological stasis for such a long period may be possible but, on the balance of evidence, would be extremely unusual. There are examples of long stasis, for example, fossil leaves identical to extant Nothofagus gunnii (Hill 1984), Telopea truncata and Lomatia fraxinifolia (Carpenter and Jordan 1997) have been found in Early Oligocene (30 -35 million years old) sediments. However, the plants that produced these leaves may have differed from the living species in other features, and in any case these are exceptional cases. Thus, Niklas et al. (1983) suggest that morphological species have a mean duration of approximately 4-5 million years, and this estimate may in fact be an overestimate since it is based on fossils, and the fossil record is biased towards species of long duration (Mclaughlin 1994). Furthermore, both Tasmania and New Zealand have both undergone environmental changes on large enough scales as to restrict almost any plant species to refugia at some stage (e.g. Kirkpatrick and Fowler 1998), which would favour micro-evolution.

Wide disjunctions within species are sometimes due to incomplete knowledge of the taxa, i.e. the disjunct species may be better described as separate species. Hill and Orchard (1999) describe such a situation in Myriophyllum, where one disjunct species was split into five species, each endemic to a major landmass. However, they do emphasise that these species are very closely related, and that the disjunction is most likely to be due to long distance dispersal. Thus, although the disjunct populations of some of the species may show some differentiation, most, if not all, will be very closely related. 
Data from disjunct species is not simple to interpret; for example, Hill and Orchard (1999) suggested that the Tasmanian species that occur in New Zealand are ones that have traits that make them amenable to long distance dispersal. They did not, however, consider the incidence of these dispersal traits in the flora as a whole, and therefore how atypical the disjunct species really are. This work, therefore, reconsiders this issue, firstly by testing if this disjunct flora is atypical of the flora as a whole in terms of dispersal traits, and secondly by creating a preliminary model of rates of long distance dispersal based on characteristics of disseminules and habitat factors. The limitations of this model, and ways to improve it are also considered.

\section{Materials and methods}

\section{Data}

This work considered all angiosperm species recorded by Buchanan (1999) as indigenous to Tasmania, except orchids. For each of these species, the following traits were scored:

1. Disjunction: whether a Tasmanian species was also native to New Zealand.

2. Habit: woody perennial; annual monocot; perennial monocot; annual dicot; perennial dicot herb.

3. Habitat: saltmarsh/estuarine aquatic; freshwater aquatic; dry coastal environments; plant growing on wet peat; plant of dry inland environments; wet forests.

4. Family.

5. Alpine distribution: rarely or never in alpine zone; in both alpine and non-alpine vegetation; almost exclusively alpine.

6. Dioecy: dioecious or not. The degree to which self-fertilisation is possible will affect a species' capacity to establish new populations through long distance dispersal. This trait does not allow for self-incompatibility because these data are not available for many groups of plants (see discussion). 
7. Disseminule size. This was scored by placing the species' disseminules into categories, based on the log of the product of the longest and shortest dimensions of the body of the disseminule excluding appendages such as plumes or wings. Where a species had more than one disseminule the smaller one was used. The categories corresponded to spherical disseminules of $<0.237 \mathrm{~mm}, 0.237-0.422 \mathrm{~mm}, 0.422-0.752$ $\mathrm{mm}, 0.752-1.33 \mathrm{~mm}, 1.33-2.37 \mathrm{~mm}, 2.37-4.22 \mathrm{~mm}$ and $>4.22 \mathrm{~mm}$ respectively. This is related to wind dispersal ability, and possibly other dispersal mechanisms. A better measure of wind dispersal would be to measure drop rates of disseminules (van der Pijl 1982), but this was not practicable for the large number of species considered here.

8. Fleshy fruit: presence/absence.

9. Hooked or sticky disseminules: presence/absence. This reflects features involved in epizoochory (transport externally on animals; van der Pijl 1982). The awns of grasses were not included, although they sometimes seem to assist epizoochory (see van der Pijl 1982). However, van der Pijl (1982) considered that their primary role was in establishment. In fact, large and robust awns (i.e. those with potential for epizoochory) were under-represented among the disjunct species (only $14.7 \%$ of grasses with robust awns were disjunct compared with $18.8 \%$ without).

10. Plumosity: presence/absence of disseminules with prominent hairs, plumes or pappus. Note that wings were not included in this trait because the winged seeds in the Tasmanian flora were all heavy and not likely to be wind dispersed.

11. Abundance: three levels: $0=$ very rare (classified as endangered or vulnerable by Kirkpatrick et al. 1991), 1 = rare (other species listed as rare by Kirkpatrick et al. 1991), $2=$ common (others).

These data were collected from floras and vegetation descriptions of Australia and New Zealand (Allen 1961; Curtis 1963, 1967; Moore and Edgar 1970; Curtis and Morris 1975, 1994; Harden 1990, 1991, 1992, 1993; Kirkpatrick 1997), from fresh collections, and from herbarium specimens in the Tasmanian Herbarium (HO). Species that fitted in 
more than one category were allocated to the category in which they are most common. This was most frequently a problem for habitat, for which a few species were not scored because of a lack of reliable data.

\section{Statistical analyses}

All analyses of the incidence of trans-Tasman disjunct species were made assuming a binomial distribution and a logistic link function. Simple comparisons between frequencies of different categories of each variable except family were made using the contrast statement of the GENMOD procedure of SAS (1997) since this allows pairwise contrasts. Since most analyses involved more than three classes and hence multiple comparisons, probabilities were adjusted according to the Bonferroni method (Sokal and Rohlf 1995). A more complex model simultaneously accounting for the effects of different dispersal traits was analysed using ASReml (Gilmour et al. 1999), since this program allows rigorous analysis of binomial traits with models including both random and fixed effects. The model was

disjunction $=$ mean + dioecy + habitat + size + hooks + family + family*habitat + residual

Family, family by habitat and the residual were treated as random effects and the other effects were treated as fixed effects. Note that habit was not included in the model because this effect was not significant. The interaction effects of family with the specialist dispersal features such as hooks, plumes were not included for similar reasons. The effect of hooks was included, even though it did not show significant variation, because the incidence of disjunctions was consistent with a priori expectations. In contrast, plumosity and fleshy fruit were not included as effects in the model because the incidence of disjunctions was contrary to a priori expectations. This model was fitted on a data set excluding woody plants. Predictions were made from this data by calculating generalised least squares means with ASReml (see Gilmour et al. 1999). 


\section{Results}

Frequencies of life traits in dispersed and non-dispersed species

In all, 200 species (excluding orchids) were recorded as being native to both Tasmania and New Zealand. This constitutes $15.2 \%$ of the Tasmanian flora (excluding orchids) and $11.6 \%$ of the 1728 non-orchid species in New Zealand's flora recognised by Allan (1961), Moore and Edgar (1970) and Edgar and Connor (1999). Only 2.8\% of the trees or shrubs were disjunct, but approximately $22 \%$ of herbs were disjunct, with very little difference between monocots and dicots, or between annual and perennial herbs (Fig. 1). Since the incidence of disjunct woody species is too low for useful analysis, the analyses below were restricted to herbaceous taxa. Note, however, that as with the herbaceous taxa, coastal and small seeded taxa were well represented among the disjunct woody plants (Table 1).

High proportions of the species growing in saltmarshes or estuaries, lakes and rivers, on waterlogged peats, or in dry coastal environments had trans-Tasman disjunct distributions (Fig. 2). In contrast, low proportions of the species of dry, non-coastal environments or wet forests had trans-Tasman disjunctions.

There were also large differences among disseminule size classes (Fig. 3). In particular, high proportions of the species with disseminules in the two small classes had disjunct distributions. Also, the third largest class had a significantly lower proportion of disjunct species than all the other classes.

A slightly lower proportion of alpine herbs showed disjunct distributions than lowland herbs, with an intermediate proportion for species which occurred in both habitats, although the differences were not significant ( $P>0.05$; Fig. 4$)$.

The proportion of disjunct species within the group with specialist features for wind dispersal (hairs, plumes or well-developed pappi) was not greater than the proportion without such features (Fig. 5). This was not due to the relatively low incidence of dispersal in Asteraceae because the incidence of disjunct species with plumes or hairs was not substantially altered when Asteraceae was excluded. Similarly, specialist features for external transport on animals (hooks, barbs or sticky seeds) were slightly over-represented among the disjunct species (Fig. 5), although this was not statistically significant. Perhaps surprisingly, a significantly low $(P<0.05)$ proportion of fleshy fruited had disjunct distributions (Fig. 5). There was significant variation among families and also among habitats within families in the incidence of disjunct species 
(Fig. 6). A significantly lower proportion of dioecious species was disjunct than nondioecious species (Fig. 7). Significantly lower proportions of rare and very rare species were disjunct than common species (Fig. 8).

\section{Discussion}

\section{Relationships between disjunctions and dispersal traits}

The significant impact of some disseminule features on the incidence of disjunct species suggests that these features assist long distance dispersal. In particular, significantly high proportions of the taxa with disseminules in the two very small size classes (the 'spore-like' seeds of van der Pij1 1982) had disjunct distributions. Also higher proportions of species with hooked or barbed disseminules were disjunct than those without, although this difference was not significant. Thus van Steenis' (1979) argument against long distance dispersal, that disjunctions show no association with the means of transport, appears to be untrue.

Several of the patterns in the data were unexpected, including the significantly low incidence of disjunct species third largest size class (equivalent to a spherical seed of 1.8 mm diameter). Although most fleshy-fruited taxa had disseminules in the two large size classes, this is unlikely to explain the apparent anomaly because fleshy-fruited taxa are under-represented among the disjunct species. An under-representation of fleshy-fruited genera among genera likely to have reached New Zealand by dispersal was also recorded by Lord (1999). Another unexpected pattern was that the low incidence of disjunct species with plumes or hairy disseminules. However, Swenson and Bremer (1997) have demonstrated significant long-distance dispersal in Abrotanella, a daisy genus with no pappus or other obvious dispersal traits.

These data therefore show that, although some dispersal traits are well represented among the disjunct species, Hill and Orchard's (1999) assertion that most species showing disjunctions between Tasmania and New Zealand are amenable to long distance dispersal does not present a complete picture. Many disjunct species lack obvious dispersal features, and many non-disjunct species that have features that suggest a potential for dispersal. The implication is that many non-disjunct species have the potential for long distance dispersal, and past dispersal may have contributed to the biogeography of many groups. 


\section{Relationships with habit, habitat and abundance}

Few woody species had disjunct distributions (only 2.8\%), but the distinctions between monocots and dicots, or between perennials and annuals had no effect on the incidence of disjunct species (Fig. 1).

The high incidence of within species disjunctions among aquatic species (Fig. 2) has been noted previously, and has been attributed to various mechanisms such as dispersal by water birds (e.g. Jacobs and Wilson 1996). The high incidence of disjunct species in coastal environments, both aquatic and non-aquatic (Fig. 2), is also not surprising, since the plants and their disseminules are necessarily salt tolerant.

The higher incidence of disjunct species on wet, peaty soils than on well drained substrates (Fig. 2) is more difficult to explain, but it is supported empirically by the patterns in generic disjunctions at higher taxonomic levels. The montane cushion plant flora provides an excellent example. In Tasmania, these communities are mostly peat forming and create waterlogged environments, so they fall neatly into the plants growing on wet peat category. Not only are there high incidences of within species disjunctions, but almost all the other species have close relationships with species in similar habitats in many high latitude areas of the Southern Hemisphere. For many taxa, this includes not only New Zealand, Patagonia and Tierra del Fuego, but also isolated oceanic subantarctic islands and even alpine New Guinea. Thus, Swenson and Bremer (1997), demonstrated that the most parsimonious explanations of the distribution of Abrotanella, which includes one of Tasmania's cushion plants, but also species in New Guinea, New Zealand, South America, oceanic islands south of New Zealand and west of Chile, include several long distance dispersal events.

Raven (1973) sugegsted that dispersal may have been very significant for the alpine flora. The higher proportions of disjunct species among the lowland and widespread herbaceous species (Fig. 4) suggest that dispersal may have been at least as significant in the lowland flora.

Abundance appears to be very significant among disjunct species (Fig. 8). Two potential reasons are, firstly, that more abundant species will tend to produce a greater total number of disseminules than less abundant species, and, secondly, that abundance may reflect an ability to successfully grow in a wide range of habitats, and therefore improving their chances of success in a new region. However, the abundance of species undoubtedly varies through time, and the abundance of one species has little relation to 
the abundance of its close relatives, so the present abundance in the current vegetation is not informative in predicting the potential for long distance dispersal in the distant past. That is, abundance cannot be used in models of long-distance dispersal, except for predicting current or recent rates.

Do the differences in incidence of disjunct species reflect differences in evolutionary rates?

Differences in evolutionary rates may have affected the observed patterns in the incidence of within-species disjunctions. Thus, fast evolving forms will be recognised as a separate species long before slow evolving forms, and hence biasing the sample of disjunctions. For instance the disjunct species could occur in slow evolving taxonomic groups or might be slower evolving than their relatives, and the predictive model may overestimate dispersal rates. However, there is no sign that that either of these is true. For example, if the size of a family is a rough indication of the rates of evolution in that family, then the expectation would be that the incidence of disjunct species should be negatively associated with the size of the family. In fact, there is no association:

Kendall's rank correlation between the incidence of disjunct species and the worldwide number of species in a family is 0.02 , which is positive, extremely weak and not significant. These issues could be tested as described below.

\section{The model of long-distance dispersal}

\section{Predictions}

Predictions of the underlying probability of a disjunction can be made for any combination of family, dioecy, habit, habitat, disseminule size and hooks, or any subset of these characters. If evolutionary rates are assumed to be constant among taxa, and an assumption is made about the critical time for disjunct populations to have evolved enough to be recognised as different species, then the model can be used to make predictions of the frequency of dispersal. An example in a group with high rates of disjunction is that typical Juncaceae (small seeded, dioecious plants of wet environments) have a probability of $0.37 \pm 0.06$ trans-Tasman dispersal events per species. If the mean species duration in this group of plants were 1 million years, then over several million years such a dispersal event would be very likely. The 1 million years is possibly an over-estimate considering the estimates of several million years for 
long-lived fossil morphospecies given in the introduction and factors that would favour rapid morphological evolution. These factors include the volatile environments of the last few million years, the allopatric nature of the populations under consideration and the likelihood that dispersal would create very small populations. Even in groups with much lower levels of disjunction, predicted dispersal rates are reasonably high. For example, typical asteraceous herbs of dry grasslands or forests would have a predicted rate of $0.17 \pm 0.03$ trans-Tasman dispersal events per species per million years, which, over long periods would predict many dispersal events.

The results presented here make no inference as to the direction of dispersal. It is plausible that most trans-Tasman dispersal is from west to east (i.e. Tasmania to New Zealand), partly because of the generally westerly winds at these latitudes, and partly because of fossil evidence suggesting that this is the case (e.g. Macphail 1997). Dispersal in the opposite direction also appears to occur. For example, Macphail (1997) cites palynological evidence to suggest that Astelia dispersed from New Zealand to Australia. Also, most of Swenson and Bremer's (1997) proposed dispersal events in Abrotanella were from east to west. The results presented here also do not estimate for dispersal across other ocean barriers, although it is likely that there would similarities in the relative rates for different taxa or different ecological groups. The relative rates of dispersal across other barriers could be estimated by expanding the model here to include data from other disjunct areas. For example, species disjunction data from oceanic islands from many parts of the world, between oceanic islands and nearby continental landmasses, and between long disjunct continental areas (such as Madagascar and South Africa) could be analysed simultaneously with the data presented here.

\section{Assumptions and testability}

The preliminary model proposed here makes a number of simplifying assumptions that may not be satisfied in real systems. Phylogenetic effects may affect the results. Evolutionary comparative methods attempt to deal with such problems, but the lack of a robust phylogeny for all Tasmanian angiosperms prohibits their use, except possibly to test aspects of the model. However, phylogenetic effects may not be significant since variation in the type of dispersal traits has little effect on the incidence of disjunct species. For example, within Tasmanian Cyperaceae, Uncinia species have a hooked 
utricle for exozoochory, Carex species have a utricle which may be involved in flotation or for attachment to birds feet (van der Pijl 1982), Carpha species have persistent plumose perianth that apparently assists in wind dispersal, the fruit of Baumea species have spongy mesocarp that may assist in flotation, and in other genera the seeds lack conspicuous dispersal features. However, approximately $1 / 3$ of the species in each of these groups is disjunct (8/25 in Carex, 1/3 in Carpha, 2/6 in Uncinia, 4/8 in Baumea and 29/82 in the others). Thus it would appear that many independent dispersal strategies have arisen in the family. The implication is that dispersal is a primarily an ecological trait in this family, rather than a purely phylogenetic one.

Another potential limitation is that the model deals only with easily observable traits. Other dispersal traits have been observed in some taxa, but the presence or absence of analogous feature in other species is unknown, and therefore these traits cannot be meaningfully incorporated in the model. For example, floating seeds occur in Potomageton (Curtis and Morris 1994), and it has been suggested that the utricle in Carex and the glumes of some grasses assists in flotation (van der Pij1 1982). Similarly many dispersal features may be poorly understood or totally unknown. Thus it is possible that the disjunct species may be a biased sample for unknown reasons. However, the incorporation of family and habitat effects in the model will compensate for the effects of many of these factors.

The final problem is with the assumption of even rates of evolution. This is unlikely to be true, although the range in rates is unknown. However, as noted above, the rates of disjunction are not correlated with family size (as a proxy for evolutionary rates), suggesting that there is no bias involved here. Alternative models including the effects of different rates of cladogenesis for different lineages could be investigated to partially overcome this difficult problem.

To deal with these limitations, the model may be tested with independent data sets. Firstly, the validity of assuming that the within-species disjunctions are due to long distance dispersal as opposed to vicariance may be tested using molecular clock methods (e.g. Page 1990), particularly on non-coding regions of the genome, which should be independent of the morphological divergence. Although rates of molecular evolution vary, so that molecular clocks can be inaccurate, the differences between expected times of levels of divergence under dispersal and vicariant hypotheses are very great. Molecular clock methods could also be used to test the model's predictions, for 
example, through comparisons among pairs of closely related, but disjunct species. The degree of molecular divergence between the species pairs should be correlated with the predicted dispersal rates for those taxa. Analyses of specific test cases using molecular clock methods would also be very interesting. For example, the model here predicts high dispersability for Donatiaceae. However, this small (and perhaps slowly evolving) family of only about three species of cushion plants occurs in Tasmania, New Zealand and South America, and has been suggested as a case of Gondwanan vicariance. Similar arguments apply to groups such as Gunnera, Astelia, Liberia, Colobanthus and Cortaderia and a variety of others. Swenson and Bremer's (1997) treatment of Abrotanella also fits into this category. Finally similarity between the patterns observed here and those in disjunctions of other land masses could be used as a test, firstly of the patterns reported here apply for ecologically distinct areas (e.g. wet tropics and subtropics, dry temperate areas), and secondly whether the patterns are the result of species specific effects. That is, if the different species, genera and families found in other regions show the same associations of disjunctions with habitat and disseminule types found for Tasmania/New Zealand disjunctions, then the patterns are unlikely to be due to phylogenetic idiosyncrasies.

\section{Acknowledgments}

I thank Robert Hill, Peter Weston, Steve McLaughlin and Tim Brodribb for discussion and advice.

\section{References}

Allen HR (1961) 'Flora of New Zealand, Vol. 1.' (R. E. Owen, Government Printer: Wellington, New Zealand)

Van Balgooy, MMJ (1960). Preliminary plant-geographical analysis of the Pacific.

Blumea 10, 383-430.

Van Balgooy, MMJ (1971). Plant-geography of the Pacific. Blumea Supplement 6.

Buchanan AM (1999) 'A Census of the Vascular Plants of Tasmania.' (The Tasmanian Herbarium: Hobart)

Carlquist S (1974) 'Island Biology.' (Columbia University Press: New York) 
Carpenter RJ, Jordan GJ (1997) Early Tertiary macrofossils of Proteaceae from Tasmania. Australian Systematic Botany 10, 533-563.

Curtis WM (1963) 'The Student's Flora of Tasmania, Vol. 2.' (Tasmanian Government Printer: Hobart)

Curtis WM (1967) 'The Student's Flora of Tasmania, Vol. 3.' (Tasmanian Government Printer: Hobart)

Curtis WM, Morris DI (1975) 'The Student's Flora of Tasmania, Vol. 1, 2nd edn.' (Tasmanian Government Printer: Hobart)

Curtis WM, Morris DI (1994) 'The Student's Flora of Tasmania, Vol. 4.' (Tasmanian Government Printer: Hobart)

Edgar E, Connor HE (1999) 'Flora of New Zealand Vol. 4.' (Manaaki Whenua Press: Lincoln, New Zealand)

Gilmour AR, Thompson R, Cullis BR, Welham SJ (1999) 'ASReml, Unpublished manual'. (NSW Agriculture: Orange)

Harden GJ (1990) 'Flora of New South Wales, Vol. 1.' (New South Wales University Press: Sydney)

Harden GJ (1991) 'Flora of New South Wales. Vol. 2.' (New South Wales University Press: Sydney)

Harden GJ (1992) 'Flora of New South Wales, Vol. 3.' (New South Wales University Press: Sydney)

Harden GJ (1993) 'Flora of New South Wales, Vol. 4.' (New South Wales University Press: Sydney)

Hill RS (1984) Tertiary Nothofagus macrofossils from Cethana, Tasmania. Alcheringa 8, 81-86.

Hill RS, Orchard AE (1999) Composition and Endemism of Vascular Plants. In 'Vegetation of Tasmania'. (Eds JB Reid, RS Hill, MJ Brown and MJ Hovenden) pp. 89 - 124. (Australian Biological Resource Study: Melbourne)

Jacobs SWL (1999) Terrestrial Wetland and Water Plants. Flora of Australia 1, 403416.

Jacobs SWL, Wilson KL (1996) Biogeographical analysis of the freshwater plants of Australasia. Australian Systematic Botany 9, 169-183.

Kirkpatrick JB (1997) 'Alpine Tasmania: an illustrated guide to the flora and vegetation.' (Oxford University Press: Melbourne) 
Kirkpatrick JB, Fowler M (1998) Locating likely glacial forest refugia in Tasmania using palynological and ecological information to test alternative climatic models. Biological Conservation 85, 171-182.

Kirkpatrick JB, Gilfedder L, Hickey J, Harris S (1991) 'Reservation and conservation status of Tasmanian native higher plants'. (Department of Parks, Wildlife and Heritage Wildlife Division: Hobart)

Linder HP, Crisp MD (1995) Nothofagus and Pacific biogeography. Cladistics 11, 5-32.

Lord J (1999) Fleshy-fruitedness in the New Zealand flora. Journal of Biogeography 26, 1249-1253.

Macphail MK (1997) Comment on M. Pole (1994): The New Zealand Flora - entirely long distance dispersal? Journal of Biogeography 21, 113-114.

McLaughlin SP (1994) Floristic plant geography: the classification of floristic areas and floristic elements. Progress in Physical Geography 18, 185-208.

Mildenhall DC (1980) New Zealand late Cretaceous and Cenozoic plant biogeography: a contribution. Palaeogeography, Palaeoclimatology, Palaeoecology 31, 197-233.

Moore LB, Edgar E (1970) 'Flora of New Zealand vol. 2.' (A. R. Shearer, Government Printer: Wellington)

Nelson G, Platnick N (1981) 'Systematics and Biogeography.' (Columbia University Press: New York)

Niklas KJ, Tiffney BH, Knoll AH (1983) Patterns in vascular plant diversification. Nature 303, 614-616.

Page RDM (1990) Temporal congruence and cladistic analysis of biogeography and cospeciation. Systematic Zoology 39, 205-226.

van der Pijl L (1982) 'Principles of dispersal in higher plants.' Springer Verlag, Berlin. Pole MS (1994) The New Zealand flora - entirely long distance dispersal. Journal of Biogeography 21, 625-635.

Raven PH (1973) Evolution of subalpine and alpine plant groups in New Zealand. New Zealand Journal of Botany 11, 177-200.

SAS Institute Inc. (1997) 'SAS/STAT Software: Changes and Enhancements through Release 6.12.' (SAS Institute Inc.: Cary, NC)

Savolainen V, Chase MW, Hoot SB, Morton CM, Soltis DE, Bayer C, Fay MF, de Bruijn AY, Sullivan S, Qiu Y-L (2000). Phylogenetics of flowering plants based on 
combined analysis of plastid $a t p$ B and $r b c \mathrm{~L}$ gene sequences. Systematic Biology 49 , 306-362.

Shaw RG (1991) The comparison of quantitative genetic parameters between populations. Evolution 45, 143-151.

Sokal RR, Rohlf FJ (1995) 'Biometry, 3rd Edn.' (W. H. Freeman and Company: San Francisco)

van Steenis CGGJ (1979) Plant Geography of East Malaysia. Botanical Journal of the Linnean Society 79, 97-178.

Swenson U, Bremer K (1997) Pacific biogeography of the Asteraceae genus Abrotanella (Senecioneae, Blennospermatinae). Systematic Botany 22, 493-508.

Wilford GE, Brown PJ (1994) Maps of late Mesozoic-Cenozoic Gondwana break-up: some palaeogeographical implications. In ' History of the Australian Vegetation: Cretaceous to Recent'. (Ed. RS Hill) pp. 5-13. (Cambridge University Press: Cambridge)

Woodland DW (1997) 'Contemporary Plant Systematics' (Andrews University Press: Michigan) 
Table 1. Woody Tasmanian species that are also native to New Zealand

For fleshy fruits the size is of the endocarps or seeds

\begin{tabular}{|c|c|c|}
\hline Family/Species & Habitat & Disseminule \\
\hline \multicolumn{3}{|l|}{ Chenopodiaceae } \\
\hline Atriplex billardierei & beach & $5 \mathrm{~mm}$ \\
\hline Sarcocornia quinqueflora & saltmarsh & $1 \mathrm{~mm}$ \\
\hline \multicolumn{3}{|l|}{ Epacridaceae } \\
\hline Cyathodes juniperina & wet forest & fleshy, $7 \mathrm{~mm}$, \\
\hline Leucopogon parviflorus & coastal heath & fleshy, $4 \mathrm{~mm}$, \\
\hline Pentachondra pumila & alpine heath & fleshy, $3 \mathrm{~mm}$ \\
\hline Sprengelia incarnata & wet heath & $0.5 \mathrm{~mm}$ \\
\hline \multicolumn{3}{|l|}{ Ericaceae } \\
\hline Gaultheria depressa & rocky alpine areas & $0.4 \mathrm{~mm}$ \\
\hline \multicolumn{3}{|l|}{ Myrtaceae } \\
\hline Leptospermum scoparium & wet \& dry heath \& woodland & $2 \mathrm{~mm} \times 0.3 \mathrm{~mm}$ \\
\hline \multicolumn{3}{|l|}{ Polygonaceae } \\
\hline Muehlenbeckia axillaris ${ }^{\mathrm{A}}$ & moist rocky places & $3 \mathrm{~mm}$ \\
\hline \multicolumn{3}{|l|}{ Rhamnaceae } \\
\hline Pomaderris apetala & wet forest & $2 \mathrm{~mm} \times 0.5 \mathrm{~mm}$ \\
\hline Pomaderris phylicifolia & riparian & $2 \mathrm{~mm} \times 0.5 \mathrm{~mm}$ \\
\hline \multicolumn{3}{|l|}{ Sapindaceae } \\
\hline Dodonaea viscosa & wet and dry forest & $1 \mathrm{~mm}+$ wing \\
\hline \multicolumn{3}{|l|}{ Solanaceae } \\
\hline Solanum laciniatum & disturbed wet forest & fleshy, $2 \mathrm{~mm}$ \\
\hline
\end{tabular}

${ }^{\mathrm{A}}$ M. axillaris is dioecious. 
Figures

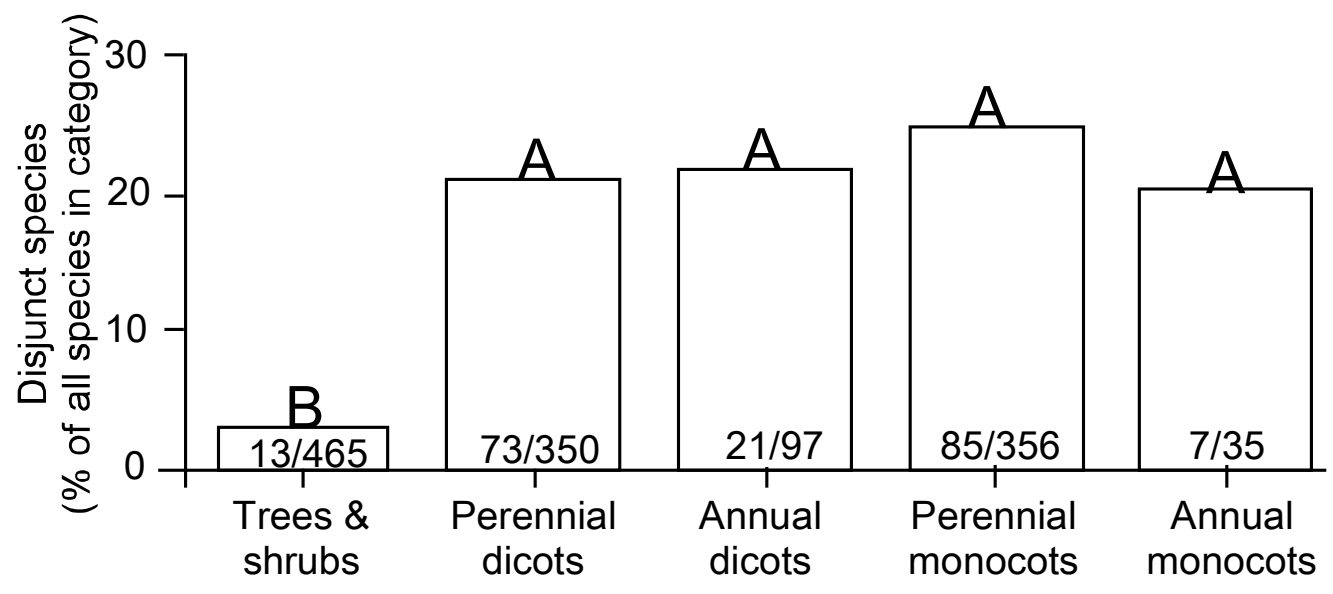

Fig. 1. Proportions of Tasmanian species that also occur in New Zealand, by habit. The numbers at the base of columns are of species with disjunct distributions followed by the total with that habit. The letters above the columns indicate the results of significance tests, different letters indicate significantly $(P<0.05)$ different frequencies.

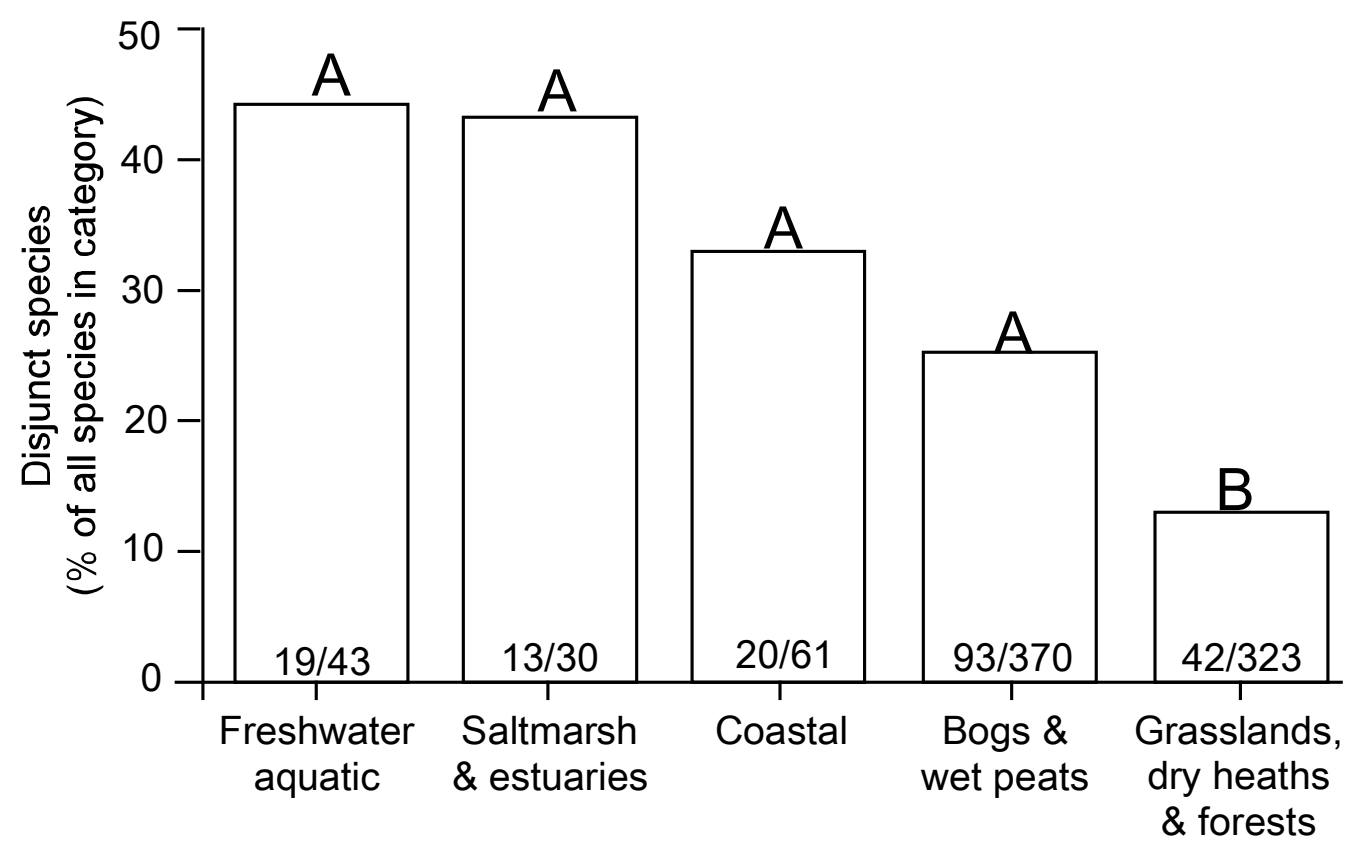

Fig. 2. Proportions of Tasmanian herbaceous species that also occur in New Zealand, by habitat. Symbols follow Fig. 1. 


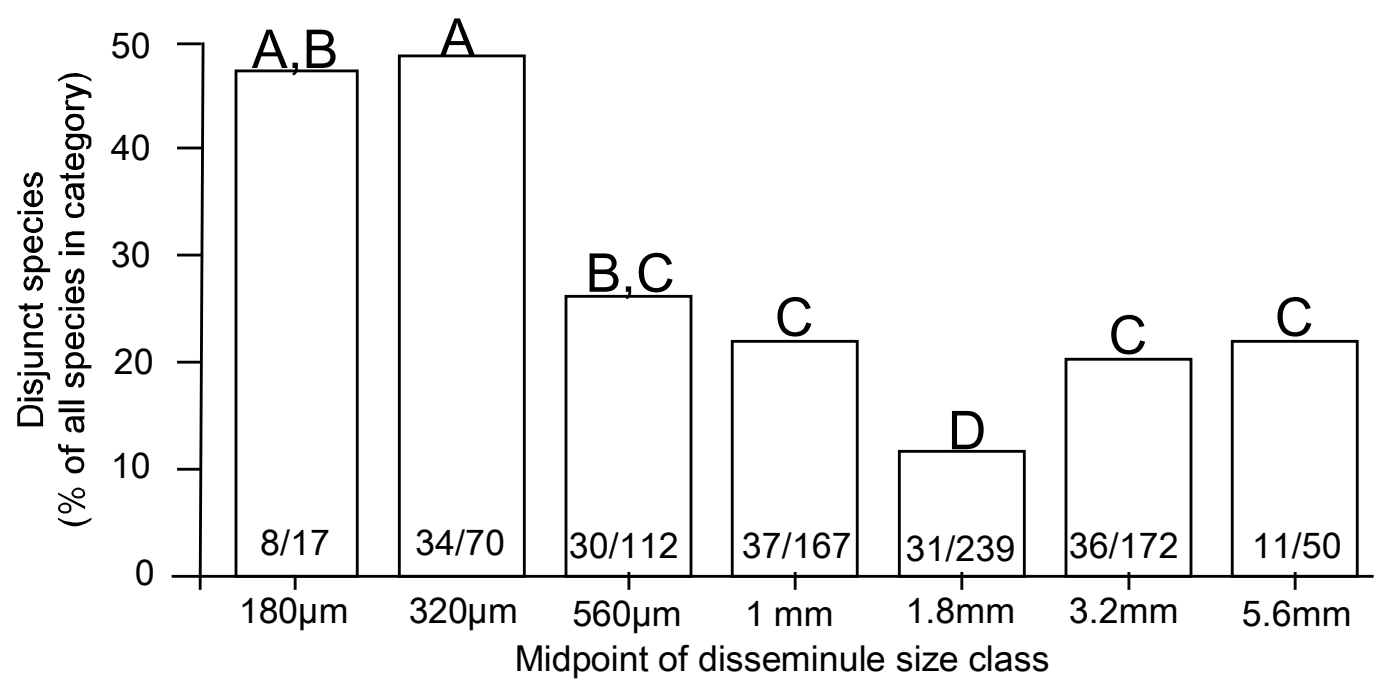

Fig. 3. Proportions of Tasmanian herbaceous species that also occur in New Zealand, by size of disseminules. Symbols follow Fig. 1. Midpoints of the classes are based on spherical seeds.

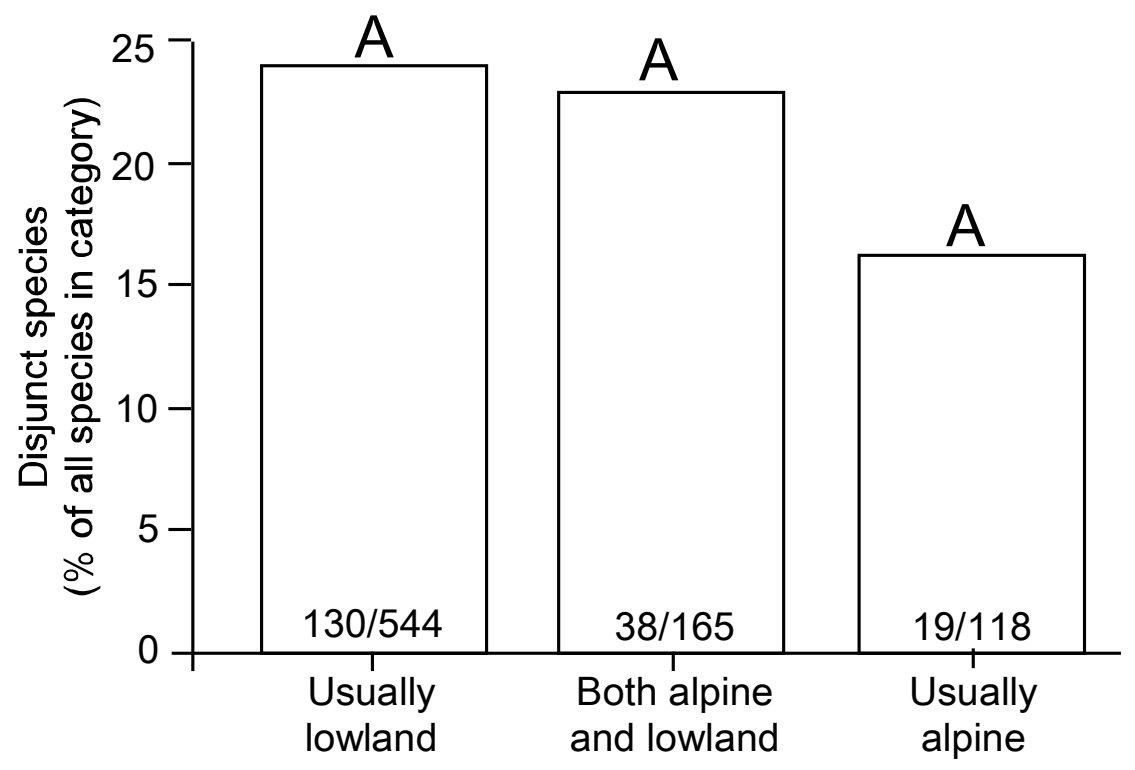

Fig. 4. Proportions of Tasmanian herbaceous species that also occur in New Zealand, by occurrence in alpine environments. Symbols follow Fig. 1. 


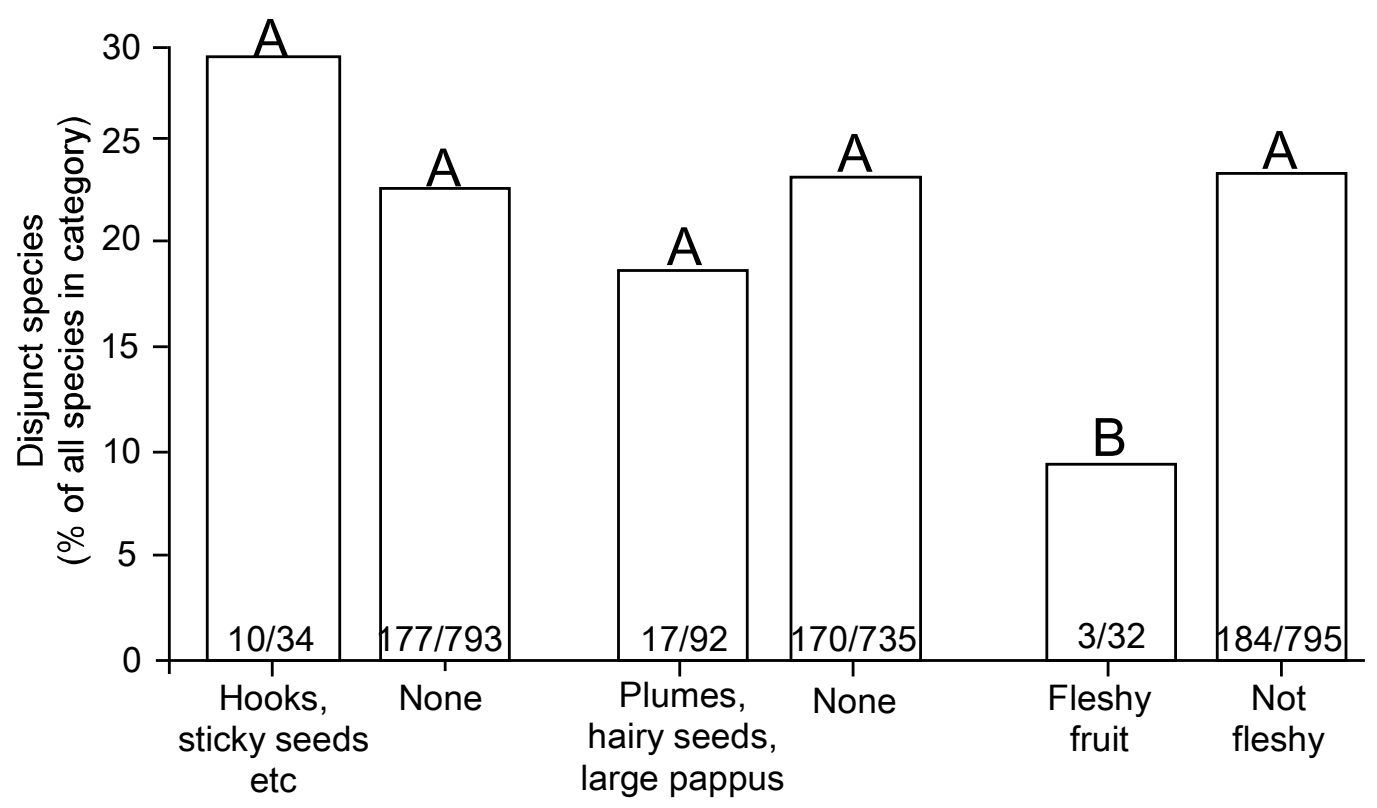

Fig. 5. Proportions of Tasmanian herbaceous species that also occur in New Zealand according to the presence or absence of some specialised dispersal features. Symbols follow Fig. 1.

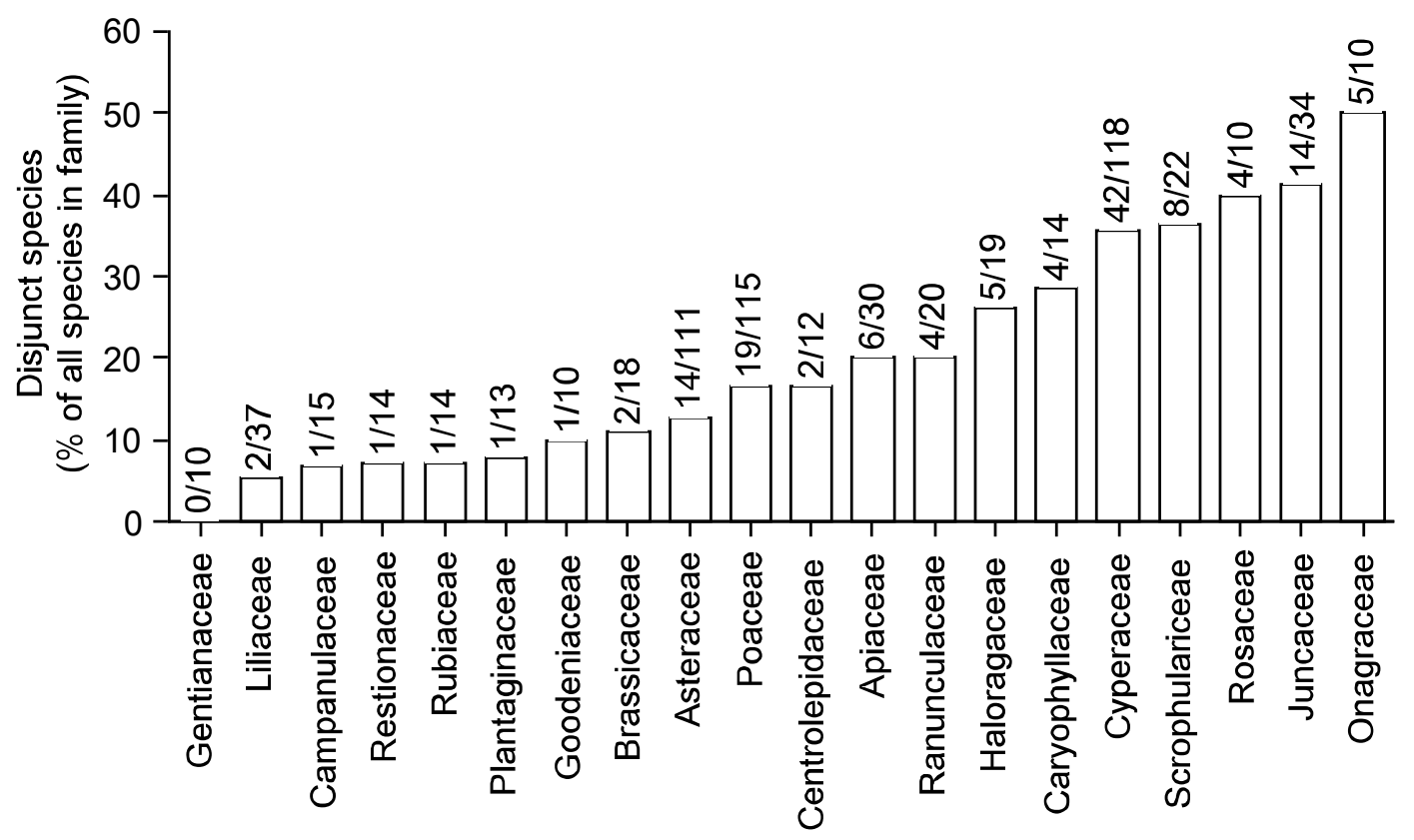

Fig. 6. Proportions (by family) of Tasmanian herbaceous species that also occur in New Zealand. Only families with more than 10 species are shown here. Numbers of nondisjunct and totals are given above the columns. 


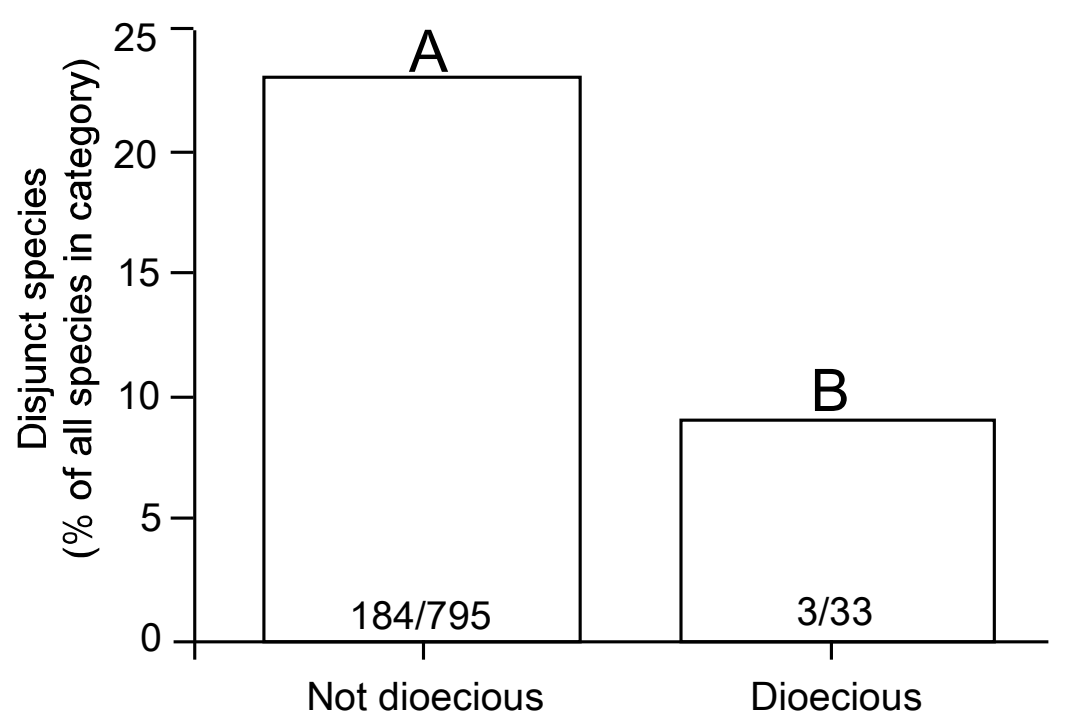

Fig. 7. Proportions (by dioecy) of Tasmanian herbaceous species that also occur in New Zealand. Symbols follow Fig. 1.

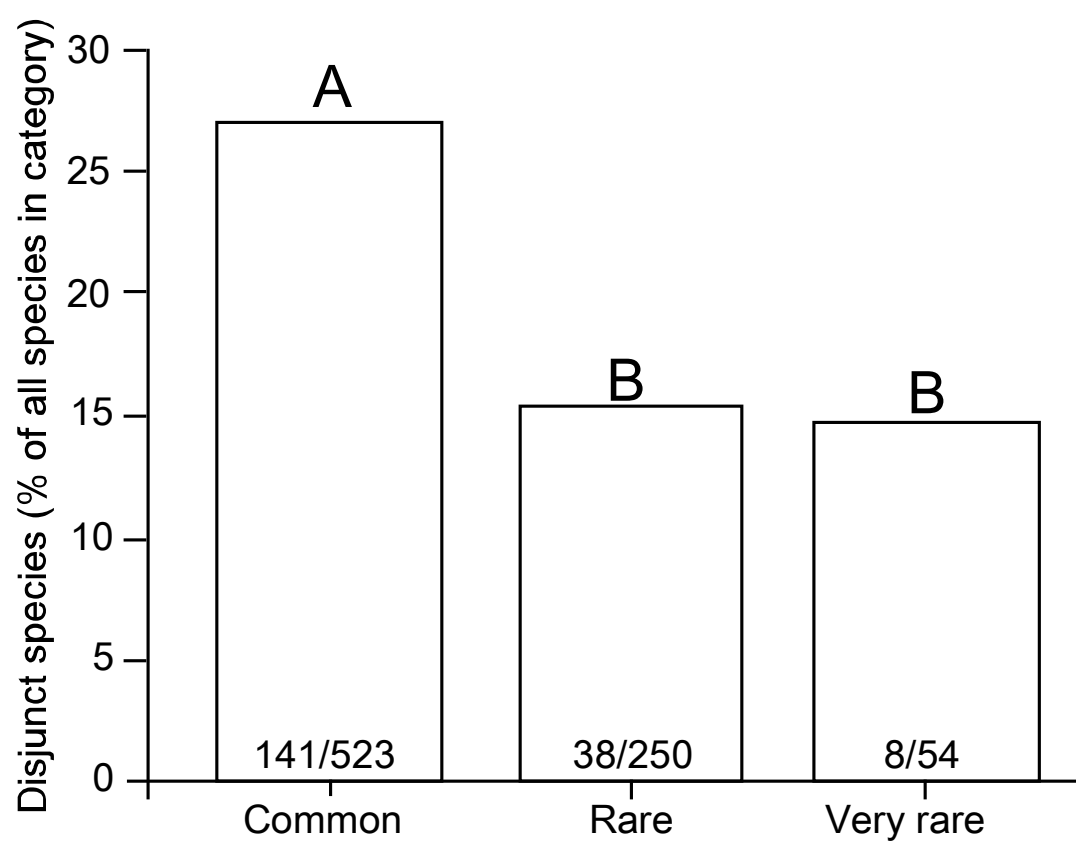

Fig. 8. Proportions (by abundance in Tasmania) of Tasmanian herbaceous species that also occur in New Zealand. Symbols follow Fig. 1. 